Justicia Juris, ISSN 1692-8571, Vol. 8. Nº 2. Julio-Diciembre 2012 Pág. 27-40

\title{
Poder sin control: La imposibilidad de adelantar procesos para exigir responsabilidades a los jueces en Colombia
}

\section{Power without control: The impossibility of start a responsibility action against judges in Colombia}

\author{
MIGUEL ANGEL GARCÉS VILLAMIL \\ Abogado y Especialista en Derecho de Sociedades, Magister en Ciencias del Estado, Doctorante en Ciencia Politica \\ de la Universidad de Belgrano en Argentina. \\ Docente universitario. Abogados asociados \\ magarcesvillamil@yahoo.es
}

Recibido: Septiembre 18 de 2012

Aceptado: Noviembre 20 de 2012

\begin{abstract}
RESUMEN
La existencia de pesos y contrapesos en un Estado de Derecho garantiza la libertad y promueve el control entre los poderes públicos. En Colombia a partir de 1991 el poder judicial ocupa una posición preponderante. El nuevo rol de los jueces les ha permitido ganar un importante espacio de influencia en las decisiones del Estado. Aunque formalmente están diseñados los mecanismos legales para investigar la actividad de miembros de las Altas Cortes de Justicia cuando cometen acciones contrarias a la ley, en la realidad no ha sido posible poner en marcha estas normas. Como consecuencia de lo anterior existe de hecho una especie de intangibilidad de los jueces, la cual impide que sean investigados o procesados cualquiera sea su conducta. En este articulo de reflexión sobre el tema se plantea la necesidad de una reforma que permita activar los mecanismos de control a los jueces para impedir la existencia de poderes sin control y hacer realidad el principio de igualdad de los ciudadanos ante la ley.

Palabras clave: División de Poderes, Independencia Judicial, Juicio, Poder Judicial, Reforma. Responsabilidad.

ABSTRACT

The existence of checks and balances in a state of law ensures freedom and promotes the control between the public authorities. In Colombia from 1991 the judicial branch of power occupies a leading position. The new role of the judges in the judicial system has changed. Therefore, they are able to win an important space influencing the decisions of the State. Although there are legal mechanisms designed to investigate the activity of members of the high courts of justice when they commit acts contrary to the law, in reality it has not been possible to implement these rules. As a consequence of the foregoing, there is in fact a kind of inviolability of judges, which prevents them from being investigated or prosecuted for their conduct. This research aims to propose a reform to enable the control of the judge's conducts, which is necessary to prevent the existence of powers without control and realize the principle of equality of citizens above the power of state.

Key words: Division of Powers, Judicial Independence, Judgment, trial, reform, Responsibility.
\end{abstract}




\section{Introducción}

Uno de los elementos fundacionales de los Estados democráticos fue la búsqueda de un mecanismo que permitiera limitar el poder de los gobernantes con la finalidad de garantizar la igualdad y libertad de los individuos. Los sistemas parlamentarios y presidencialistas han configurado, cada uno a su manera, un sistema de pesos y contrapesos entre los órganos legislativo y ejecutivo para lograr este objetivo.

Las reformas constitucionales realizadas en la mayoría de los países sudamericanos a partir de la década de los noventa incluyó la constitucionalización de un amplío catálogo de derechos y garantías sociales que pueden ser exigidos ante autoridades judiciales. Con la finalidad de adaptar la estructura del Estado al nuevo modelo constitucional algunos países crearon Tribunales Constitucionales encargados de hacer respetar las normas de la Carta Fundacional.

En el caso de Colombia, con la reforma constitucional de 1991, se creó la Corte Constitucional y el Consejo Superior de la Judicatura, que junto con la Corte Suprema de Justicia y el Consejo de Estado, configuran la cúpula de la rama judicial con un total de 75 magistrados.

El desarrollo del funcionamiento del Estado durante los 20 años posteriores a la Constitución de 1991, demuestra que la rama judicial ha tenido un papel preponderante en las más importantes decisiones estatales durante este lapso en los campos más diversos, situación que ha generado una inevitable inercia de poder a su favor, desplazando silenciosamente al poder legislativo y ejecutivo, pues sus decisiones, especialmente en materia constitucional, parecen suplir a las otras ramas del poder público.

Aunado a lo anterior, no existe procedimiento legal eficaz que permita que los miembros de la máxima jerarquía de la rama judicial puedan ser investigados por las faltas que cometan en desarrollo de sus funciones.

Los magistrados de los altos tribunales son beneficiados por un fuero constitucional el cual establece que toda investigación en su contra deba ser adelantada por el Congreso de la República, institución que jamás ha podido ejercer está función.

En este artículo se emplea el método del "Análisis de Caso", para verificar desde la perspectiva de Colombia, los aspectos que impiden el control de las actuaciones de los jueces que vulneran el ordenamiento jurídico y las consecuencias que ello tiene sobre la organización estatal. Partiendo de la existencia de instituciones formales dise- ñadas para exigir responsabilidades al poder judicial que no funcionan, para luego deducir la existencia de instituciones informales que tiene un espacio de influencia mayor y con tendencia a seguir avanzando de no realizarse un cambio de rumbo sobre el particular.

En los acápites uno a cuatro, se comentara el rol de la Rama Judicial en el Estado después de 1991 y se mencionaran los aspectos relacionados con el sistema de procesamiento a dignatarios del poder judicial diseñado en la Constitución.

En los acápites cinco a seis se describirán algunos aspectos históricos relativos a los procesos adelantados en el Congreso de la República contra funcionarios judiciales y la existencia de un principio de intangibilidad sobre los miembros de la cúpula de la rama judicial

En el acápite siete se realizará una propuesta que permita el adelantamiento de procesos contra los miembros de la cúpula judicial.

Finalmente, se expondrán las conclusiones del presente escrito, indicando que no es saludable en un Estado de Derecho establecer como principio la irresponsabilidad de los miembros de uno de los poderes públicos, debido a que son esta clase de situaciones las generadoras de desigualdad y violencia en nuestra sociedad.

\section{El poder judicial como institución y su necesidad de fortalecimiento}

La existencia de instituciones cuyas actuaciones sean respetadas y acatadas por los miembros de la sociedad es uno de los pilares de la armonía y tranquilidad sociales. La división del poder en una pluralidad de ramas u órganos que ejecutan diferentes tareas, sin existir subordinación entre las mismos, fruto del paso del despotismo monárquico a los estados constitucionales está soportado en la idea de un pacto entre los ciudadanos que entregan libremente una parte de su libertad con la finalidad que otros semejantes de manera temporal cumplan unas funciones regladas de manera anticipada participando en la dirección de las instituciones que se ha convenido deben existir para garantizar el goce de los derechos de los individuos.

La naturaleza de la institución será formal cuando exista codificación de la misma, mecanismos externos de supervisión y sanción a cargo de terceros, mientras que la informal carece de un conjunto de normas escritas y la sanción no es aplicada por un tercero ajeno a la relación (Leiras, 2004 P 62-92). 
La función de las instituciones es disminuir la incertidumbre, resolver los conflictos, estabilizar los intereses de los agentes económicos y los actores políticos e inducir a las personas a organizar sus actividades (Vargas, 2005).

El sistema judicial encargado de fallar las diferencias entre particulares o entre éstos y el Estado representado por sus jueces es una de las instituciones formales más reconocida. La idea de entregar la facultad de diferir los conflictos a una institución ajena al Presidente y Parlamento tuvo en Montesquieu uno de sus promotores, cuando indicaba en su obra el Espíritu de las Leyes:

...Cuando el poder legislativo y el poder ejecutivo se reúnen en una misma persona o el mismo cuerpo, no hay libertad; falta la confianza porque puede temerse que el monarca o el Senado hagan leyes tiránicas y las ejecuten ellos mismos tiránicamente. No hay libertad si el poder de juzgar no está bien deslindado del poder legislativo y del poder ejecutivo. Si no está separado del poder legislativo, se podría disponer arbitrariamente de la libertad y la vida de los ciudadanos; como que juez sería legislador. Si no está separado del poder ejecutivo, el juez podría tener la fuerza de un opresor. Todo se habría perdido si el mismo hombre, la misma corporación de próceres, la misma asamblea del pueblo ejerciera los tres poderes: el de dictar las leyes, el de ejecutar las resoluciones públicas y el de juzgar los delitos o los pleitos entre particulares (Montesquie, 2002) Esa concepción de un poder judicial autónomo e independiente se incrustó en el desarrollo constitucional desde la Constitución Estadounidense y la Revolución Francesa hasta hoy. ${ }^{1}$

El Banco Interamericano de Desarrollo (BID) ha promovido desde 1994 programas que apoyen el fortalecimiento institucional del poder judicial, teniendo como una de sus finalidades la consolidación de la independencia de los órganos judiciales (Carrillo, 1999).

El proyecto sobre Independencia y Acceso a la Justicia en América Latina, iniciativa que surgió a principios de 2008 en el seno de la Asamblea Permanente por los Derechos Humanos (APDH) con el apoyo de la Agencia Española de Cooperación Internacional para el Desarrollo (AECID), y con la colaboración del Relator Especial de Naciones Unidas sobre Independencia de Jueces y Abogados, tiene entre sus objetivos el fortalecimiento del sistema judicial

\footnotetext{
"Toda sociedad en la cual no esté establecida la garantía de los derechos, ni determinada la separación de los poderes, carece de Constitución". Artículo 16 de la Declaración de los Derechos del Hombre y el Ciudadano del 26 de agosto de 1789.
}

mediante la promoción de la independencia del poder judicial como uno de los objetivos ${ }^{2}$

Pareciera que es una preocupación permanente para varios países latinoamericanos la debilidad de las instituciones que representan el poder judicial. Este trabajo quiere resaltar como la fórmula adoptada por Colombia a partir de la Constitución de 1991, no sólo fortaleció el poder judicial sino que amplió su influencia en las decisiones fundamentales del Estado. Este nuevo estatus de poder cambió severamente el sistema de pesos y contrapesos entre poderes públicos, inclinando la balanza a favor de los jueces, quienes por los desarrollos de la jurisprudencia constitucional parecen tener poderes omnímodos. La otra cara de este nuevo diseño institucional es que sus principales protagonistas no están sometidos a vigilancia diferente a su prudencia, indicando que a veinte años de expedición de la nueva Carta Política no se han adelantado procesos judiciales en su contra, a pesar de actuaciones públicas que de haberlas realizado funcionarios diferentes a éstos hubieran tenido como consecuencia el inicio de acciones disciplinarias y/o penales.

\section{El rol del Poder Judicial en Colombia después de la Constitución de 1991}

La incorporación de una importante gama de derechos fundamentales, sociales, económicos, culturales, colectivos y del ambiente realizada por el constituyente de 1991 y la creación de acciones constitucionales que permiten a los ciudadanos acudan ante los jueces a solicitar la protección de ellos han producido un cambio en la función de los jueces.

La Carta Política diseño una serie de acciones que tienen por finalidad hacer respetar los derechos mencionados. De esta manera, mediante la Acción de Tutela cualquier persona que considere que sus derechos fundamentales se encuentran amenazados o pueden ser objeto de amenaza, puede solicitar a un juez de la República mediante un proceso expedito que se verifique su cumplimiento y se ordene a entidades oficiales e incluso particulares que actúen de una manera que no afecte la esencia de estos derechos. Las Acciones Populares buscan proteger los derechos colectivos y del medio ambiente, por ello cualquier ciudadano puede denunciar ante un juez la vulneración de estos derechos y solicitar medidas correctivas inmediatas tendientes a controlar la situación. La Acción de Cumplimento permite solicitar ante un juez el cumplimiento de una norma sustancial que no está siendo res-

\footnotetext{
Proyecto sobre Independencia y Acceso a la Justicia en América Latina http:/ / www.apdh-argentina.org.ar/piajal/proyecto.htm (consultado abril 16 de 2013).
} 
petada por una autoridad pública. La Acción de Grupo, mediante la cual se solicita la reparación de colectivos de personas afectados por un mismo hecho ${ }^{3}$ (arts.82 a 86 de la Constitución Política).

De otra parte, la Acción de Pérdida de Investidura, posibilita a cualquier persona solicitar ante el Consejo de Estado se ordene quitar la investidura a miembros del parlamento por violación del régimen de inhabilidades e incompatibilidades ${ }^{4}$ (Art. 184 de la Constitución Política).

La Acción de Habeas Corpus que permite solicitar la libertad a toda persona que permanezca retenida por más de treinta y seis horas sin que se notifiquen cargos en su contra y la Acción de Inconstitucionalidad, consistente en la posibilidad que tiene cualquier ciudadano de solicitar que una ley se declare contraria a la Constitución Nacional (las dos únicas acciones que consagraba la carta anterior a 1991 (Quinche, Ramírez, 2009).

La incorporación de estos mecanismos de protección .y aplicación de los derechos de los ciudadanos originó una "fiebre constitucional" consistente en la interposición masiva de las acciones mencionadas, especialmente de la acción de tutela, la cual debe ser resuelta en sólo diez días hábiles por los jueces, situación por la cual se convirtió en una herramienta de uso diarios de miembros de la comunidad.

Para dar una idea del impacto de la Acción de Tutela desde la expedición de la Constitución, debe mencionarse que la Corte Constitucional en ejercicio de sus funciones, emite sentencias de constitucionalidad cuando resuelve demandas contra normas contrarias a la Carta Política y sentencias de tutela en desarrollo de su función de revisión de fallos de esta clase de acciones, desde 1992 y hasta el 14 de octubre de 2011 ha emitido 19.128 fallos de los cuales 5.176 corresponden a sentencias de constitucionalidad y 13.952 a sentencias de tutela, lo cual indica que el $72,94 \%$ de su producción jurisprudencial hace referencia a la acción de tutela. ${ }^{5}$

Por vía de acciones de inconstitucionalidad presentadas en este periodo se despenalizó el porte de la dosis mínima o personal de estupefacientes, se permite a los médicos practicar la eutanasia a sus pacientes que tengan una enfermedad terminal y soliciten dicha acción de manera voluntaria, se permite la práctica del aborto cuando existan riesgo para la vida de la madre, tenga el feto deformacio-

Acción de Tutela, Cumplimiento, Popular y de Grupo consagrada en los artículos 86 a 88 de la Constitución Política de Colombia.

4 Acción de Pérdida de Investidura. Artículo 184 Constitución Política de Colombia.

5 Fuente: Relatoría Corte Constitucional de Colombia. nes o el embarazo hubiere sido el resultado de una acceso carnal violento.

Mediante una acción de tutela que ampara los derechos de los desplazados internos del conflicto armado, la Corte Constitucional se convirtió en la directora y supervisora de la política pública en el país, para lo cual emite órdenes al poder ejecutivo y exige rendición de cuentas sobre su fallo de los funcionarios pertenecientes a esa rama del poder público. ${ }^{6}$

Las acciones populares que son falladas por jueces de instancias menores ordenan a los gobiernos departamentales y municipales la ejecución de obras en plazos perentorios, situación que implica una modificación en los presupuestos de inversión, lo que trae como consecuencia que por cumplirse los fallos judiciales no sea posible cumplir los planes de gobierno por los cuales votaron los ciudadanos.

Ante la perspectiva de garantizar la efectividad de los derechos enunciados en la Constitución Nacional se dotó a los jueces de un poder que ejercen por medio de sus fallos desplazando a las demás ramas del poder público.

\section{Algunas consideraciones sobre el procesamiento de dignatarios de las Ramas del Poder Público en Colombia}

Durante el siglo XIX, luego de separarse definitivamente de España, la República de Colombia tuvo ocho constituciones en el lapso comprendido entre 1821 y $1886 .{ }^{7}$

La Constitución Política de 1991 derogó la Carta de 1886 y estableció el texto constitucional vigente en la actualidad en Colombia.

Desde 1821 la facultad de juzgamiento del Presidente y los miembros de la Corte Suprema de Justicia y demás altas cortes del Estado Colombiano siempre se han radicado en el Congreso de la República. De la misma manera, el juzgamiento de los miembros del parlamento compete a la Corte Suprema de Justicia.

\footnotetext{
Sentencia T-025 de 2004 Corte Constitucional. Magistrado Ponente. Manuel José Cepeda Espinosa.

7 - La Constitución de Colombia de 1821, incluía Venezuela y Ecuador.

- Constitución de Colombia sancionada el 5 de mayo de 1830.Cuatro meses después se separarían Venezuela y Ecuador.

- Constitución Política del Estado de Nueva Granada de 1832.

- Constitución de la República de Nueva Granada de 1843.

- Constitución de la República de Nueva Granada de 1853.

- Constitución Política para la Confederación Granadina de 1858.

- Constitución Política de los Estados Unidos de Colombia de 1863.

- Constitución Política de Colombia de 1886. Con diversas reformas estuvo vigente por 105 años hasta 1991.
} 
La Constitución de 1991 reiteró esa función en cabeza del Congreso, y los resultados antes y después de la última reforma a la carta política han sido siempre los mismos. Jamás ha sido acusado ningún miembro de la cúpula de la Rama Judicial por la Cámara de Representantes y ante el Senado de la República de Colombia.

Aunque lo anterior podría ser percibido como una muestra de la impoluta naturaleza de quienes tiene la tarea de administrar justicia en Colombia, también puede tener una lectura contraria, consistente en que existe una imposibilidad material de que los integrantes de la cúpula judicial puedan ser judicializados por sus conductas.

La primera década del siglo XXI se caracterizo por los procesos judiciales contra miembros del Congreso de la República por sus vínculos con organizaciones armadas al margen de la ley, especialmente a grupos denominados paramilitares o de autodefensa.

De acuerdo a datos de la Corporación Nuevo Arco Iris a julio de 2010 existían 91 congresistas procesados elegidos para el periodo 2006-2010 y 24 congresistas procesados elegidos para periodos anteriores al indicado. Más de la tercera parte del congreso elegido para el periodo 20062010 fue procesado por la Corte Suprema de Justicia.

El Congreso anualmente elige los Presidentes de Senado de la República y Cámara de Representantes, que a su vez son Presidente y Vicepresidente del Congreso de la República. Entre 1991 a 2011, han sido procesados seis expresidentes del Senado de la República y siete expresidentes de la Cámara de Representantes ${ }^{8}$, lo que da una idea de la crisis del poder legislativo en Colombia.

Con relación al poder ejecutivo, el gobierno de Ernesto Samper Pizano entre 1994 y 1998, paso la totalidad de su periodo respondiendo por un escándalo de indebida financiación de su campaña a la Presidencia por parte del "Cartel de Cali", poderoso grupo de narcotraficantes, situación que llevó a la cárcel al Tesorero y Director de su Campaña. ${ }^{9}$

$8 \quad$ Presidentes del Senado de la República: José Ramón Elías Nader (Periodo 1993-1994),Mario de Jesús Uribe (Periodo 2000-2001), Luis Humberto Gómez Gallo (Periodo 2004-2005) fueron condenados. Miguel Pinedo Vidal (Periodo 1999-2000),Javier Enrique Cáceres Leal (Periodo 2009-2010) fueron llamados a juicio. Nancy Patricia Gutiérrez Castañeda (Periodo 2007-2008) se encuentra detenida por un proceso que se encuentra en etapa de instrucción.

Presidentes de la Cámara de Representantes: César Pérez García (Periodo 1992-1993),Francisco José Jattín (Periodo 1993-1994),Emilio Martínez Rosales (Periodo 1998-1999)Armando Pomarico (Periodo 1999) fueron condenados.

9 Santiago Medina Serna, Tesorero de la Campaña y Fernando Botero Zea, Directivo de la Campaña y Ministro de Defensa entre 1994 y 1995 fueron condenados por tales hechos.
Funcionarios cercanos al Presidente Alvaro Uribe Vélez (Periodo 2002-2010) están respondiendo ante diversos estrados judiciales por acciones cometidas en el desarrollo de sus cargos. ${ }^{10}$

Los miembros del poder ejecutivo y legislativo son sujetos pasivos de procesos penales y disciplinarios que tienen como consecuencia, en algunos casos, la pérdida de sus cargos y la imposibilidad de continuar su carrera política.

Mientras todo ello ocurre, en un país que en el último lapso descubre sorprendido de manera reiterada nuevos escándalos de corrupción, la percepción de los ciudadanos sobre actitudes corruptas en los administradores de justicia tiende a aumentar.

Transparencia Internacional realiza desde el año 2003 el Barómetro Global de la Corrupción, herramienta que mide la percepción de los ciudadanos de varios países del mundo sobre las actitudes corruptas de las instituciones que los gobiernan y los efectos de las mismas en la sociedad. ${ }^{11}$

En las encuestas realizadas en Colombia desde el año 2004 a 2010, los partidos políticos y el poder legislativo aparecen como los entes que son percibidos como más corruptos por la ciudadanía. El poder judicial y la policía comparten la tercera posición entre las instituciones que son identificadas con mayores prácticas corruptas. ${ }^{12}$

El Banco Mundial mediante el proyecto Doing Business desde el año 2002 analiza y compara las normas que regulan las actividades de las pequeñas y medianas empresas locales en 183 países del mundo. Uno de los aspectos que estudia el proyecto es el cumplimiento de los contratos, y se ocupa de la eficacia en el cumplimiento de contratos, al observar cómo evoluciona una disputa judicial por la

10 Se encuentran en etapa de juicio en Andrés Felipe Arias, exMinistro de Agricultura, Bernardo Moreno Villegas, Secretario General de la Presidencia y Sabas Pretelt de la Vega, exMinistro del Interior y Embajador en Italia . Jorge Noguera Cotes, ex Director del Departamento Administrativo de Seguridad (DAS) fue condenado a 25 años de prisión por la Corte Suprema de Justicia. Salvador Arana, exEmbajador ante el gobierno de Chile fue condenado a 40 años de prisión. De igual manera están siendo procesados funcionarios medios del Ministerio de Agricultura y el DAS.

11 Desde el año 2003 la ONG Transparency International realiza las mayores encuestas mundiales multipaís sobre las experiencias y opiniones de corrupción del público en general y sobre sus perspectivas sobre dichas experiencias. Para el año 2010 fueron encuestadas más de 91.500 personas en 86 o países.

12 "A la pregunta ¿En qué medida cree que las siguientes instituciones de este país están afectadas por la corrupción? Por favor, responda en una escala de 1 a 5 , en la que 1 significa que la institución no es nada corrupta y 5 que es extremadamente corrupta" El Poder Judicial fue calificado de la siguiente manera: En 2005 3,8; 2006 3,4; 2007 3,$5 ; ; 20093,7$ y 20103,8 
venta de mercaderías y analizar el tiempo, costo y número de procedimientos necesarios desde que el abogado interpone una demanda hasta que se produce el pago. De esta manera, se realiza una medición en días calendario contados desde el momento en que el demandante presenta la demanda en el juzgado hasta el momento del pago.

Los procesos judiciales contra miembros del poder ejecutivo y legislativo parecieran ser concordantes con las percepciones de niveles de corrupción que arrojan las encuestas. No pasa lo mismo con el poder judicial, pues siendo elevada la percepción de corrupción que tienen los habitantes de Colombia y la aterradora demora para resolver sencillos procesos legales, esto no se traduce en procesos judiciales contra miembros de esta rama del poder público.

Precisamente, está es la situación que se aborda a continuación, es decir, porque existiendo percepción de corrupción en el poder judicial, no existen procesos judiciales que investiguen actividades contrarias a la ley de los administradores de justicia. Se analizara el marco constitucional y legal existente para adelantar procesos judiciales contra los máximos jerarcas de la rama judicial.

\section{Sistema Constitucional de Juzgamiento a Integrantes de Altas Cortes de Justicia en Colombia}

Previo a describir el procedimiento establecido en la Constitución colombiana para desarrollar el juzgamiento de miembros de la cúpula del poder judicial, es preciso indicar que la máxima jerarquía judicial está compuesta por la Corte Suprema de Justicia, máximo tribunal de la justicia ordinaria, compuesta por 23 magistrados, la Corte Constitucional, garante de velar por la Constitución Nacional, integrada por 9 magistrados, el Consejo de Estado, Juez Supremo de la Jurisdicción Contencioso Administrativa, conformado por 31 miembros y el Consejo Superior de la Judicatura constituido por 12 magistrados. ${ }^{13}$

13 La Corte Suprema de Justicia fue una institución existente en las siete constituciones de Colombia del Siglo XIX. Se divide en salas de asuntos penales, civiles y laborales. El Consejo de Estado fue en sus orígenes un órgano consultivo del Gobierno sin funciones jurisdiccionales según se observa en las Constituciones de 1821,1830 y 1832. Es abolido en la Constitución de 1843 y no existe mención alguna en las Constituciones de 1853,1858 y 1863. Reaparece con la Constitución de 1886 y vuelve a ser suprimido en 1905. Finalmente en 1914 se establece como máximo tribunal contencioso administrativo y órgano consultivo del Gobierno. En la actualidad se divide en la Sala de lo Contencioso Administrativo, encargada de administrar justicia, la cual a su vez se divide en cinco secciones con un total de 27 magistrados y la Sala de Consulta y Servicio Civil integrada por 4 magistrados y que emite conceptos sobre aspectos legales a petición del Gobierno Nacional. La Corte Constitucional fue creada por la Asamblea Nacional Constituyente que dio origen a la Constitución
El periodo de los magistrados en sus cargos es de ocho años no reelegibles. Estos setenta y cinco (75) funcionarios durante el ejercicio de sus funciones se encuentran beneficiados por el fuero otorgado a dignatarios de estas corporaciones por la Constitución Política de Colombia, de tal manera que cualquier proceso en su contra debe adelantarse ante el Congreso de la República de la siguiente manera.

\section{Designación de Magistrados de Altas Cortes de Justicia}

Los Magistrados de la Corte Suprema de Justicia y el Consejo de Estado son elegidos por cooptación por la Sala Plena de cada una de estas corporaciones de listas enviadas por el Consejo Superior de la Judicatura ${ }^{14}$ (art. 23 Constitución Política de Colombia).

Los miembros de la Corte Constitucional son elegidos por el Senado de la República de sendas ternas enviadas por la Corte Suprema de Justicia el Consejo de Estado y el Presidente de la República ${ }^{15}$ (art. 239 Constitución Política de Colombia).

En el Consejo Superior de la Judicatura, los miembros de la Sala Administrativa son elegidos así: dos por la Corte Suprema de Justicia, uno por la Corte Constitucional y tres por el Consejo de Estado. Mientras que los seis miembros de la Sala Disciplinaria son elegidos por el Congreso Nacional de ternas enviadas por el Gobierno ${ }^{16}$ (art. 254 Constitución Política de Colombia).

La Cámara de Representantes acusa cuando existan causas constitucionales a los magistrados de las altas cortes ante el Senado de la República. ${ }^{17}$

En la Cámara de Representantes, la Comisión de Investigación y Acusación, compuesta por 15 miembros, es la encargada de realizar la indagación sobre las denuncias presentadas contra los funcionarios que por disposición

Política de 1991. El Consejo Superior de la Judicatura, también creado en 1991, se divide en dos salas, la Administrativa, encargada de asuntos presupuestales y organizativos de la Rama Judicial y Sala Disciplinaria, con función de juzgamiento de las faltas disciplinarias de los abogados y jueces.

14 Artículo 233 Constitución Política de Colombia.

15 Artículo 239 Constitución Política de Colombia.

16 Artículo 254 Constitución Política de Colombia.

17 De Acuerdo a lo establecido en el numeral 3 del artículo 178 de la Constitución Política. Artículo 178. La Cámara de Representantes tendrá las siguientes atribuciones especiales:

3. Acusar ante el Senado, cuando hubiere causas constitucionales, al Presidente de la República o a quien haga sus veces, a los magistrados de la Corte Constitucional, a los magistrados de la Corte Suprema de Justicia, a los miembros del Consejo Superior de la Judicatura, a los magistrados del Consejo de Estado y al Fiscal General de la Nación. 
constitucional deben ser procesados por el Congreso de la República.

Una vez terminan su labor, presentan una ponencia al pleno de la Cámara de Representantes para adoptar una resolución de acusación o preclusión de la investigación adelantada.

El Senado de la República es el encargado de conocer las acusaciones realizadas por la Cámara de Representantes, con las siguientes reglas:

- Cuando se trate de delitos cometidos en ejercicio de las funciones, o a indignidad por mala conducta, solo podrá imponer la pena de destitución del empleo, o la privación temporal o pérdida absoluta de los derechos políticos.

- Cuando se trate de delitos comunes, se limitará a declarar si hay o no lugar a seguimiento de causa.

En ambos casos, el juicio donde se determine la responsabilidad penal del funcionario se adelantara ante la Corte Suprema de Justicia. ${ }^{18}$

Se observa que la función que cumple el Congreso en este tipo de juicios es la de constituirse en una instancia previa obligatoria al proceso ante la Corte Suprema de Justicia. Sin la autorización del Congreso, nunca pueden penalizarse las actuaciones de los miembros de las Altas Cortes de Justicia de Colombia.

Más que un juez, el Congreso se constituye en un supervisor de la conducta de ciertos funcionarios públicos dejando

18 Constitución Política de Colombia Artículo 174. Corresponde al Senado conocer de las acusaciones que formule la Cámara de Representantes contra el Presidente de la República o quien haga sus veces; contra los Magistrados de la Corte Suprema de Justicia, del Consejo de Estado y de la Corte Constitucional, los miembros del Consejo Superior de la Judicatura y el Fiscal General de la Nación, aunque hubieren cesado en el ejercicio de sus cargos. En este caso, conocerá por hechos u omisiones ocurridos en el desempeño de los mismos.

Artículo 175. En los juicios que se sigan ante el Senado, se observarán estas reglas:

1. El acusado queda de hecho suspenso de su empleo, siempre que una acusación sea públicamente admitida.

2. Si la acusación se refiere a delitos cometidos en ejercicio de funciones, o a indignidad por mala conducta, el Senado no podrá imponer otra pena que la de destitución del empleo, o la privación temporal o pérdida absoluta de los derechos políticos; pero al reo se le seguirá juicio criminal ante la Corte Suprema de Justicia, si los hechos lo constituyen responsable de infracción que merezca otra pena.

3. Si la acusación se refiere a delitos comunes, el Senado se limitará a declarar si hay o no lugar a seguimiento de causa y, en caso afirmativo, pondrá al acusado a disposición de la Corte Suprema.

4. El Senado podrá cometer la instrucción de los procesos a una diputación de su seno, reservándose el juicio y la sentencia definitiva, que será pronunciada en sesión pública, por los dos tercios, al menos, de los votos de los Senadores presentes. el juicio sobre la responsabilidad penal a la Corte Suprema de Justicia. La desnaturalización de su función, ha sido precisamente el adelantar procesos judiciales con las mismas formalidades y características de los procesos penales, cuando situaciones tales como la indignidad son el resultado de una apreciación subjetiva por parte de los legisladores. Un ejemplo ilustra con claridad este aspecto: Si un Magistrado de la Corte Suprema de Justicia es visto en lugares públicos consumiendo bebidas alcohólicas en compañía de delincuentes, el proceso que se tramita ante el Congreso por indignidad por mala conducta, únicamente debe girar en torno a si la actuación realizada contraria el decoro del cargo. En otra instancia, la Corte Suprema de Justicia, verificara si dicha actuación constituye un delito. Adelantar el proceso, tal como si la Cámara de Representantes en su escrito de acusación debiera demostrar el delito, es pervertir la instancia asignada por la Constitución y llevarla al estado de postración en que permanece desde siempre y que impide sancionar cuando menos con el retiro del cargo a los altos funcionarios que infringen la moral pública.

A manera de síntesis se puede afirmar: La acción u omisión cometida por Magistrados de las Altas Cortes en Colombia debe ser juzgada por el Congreso de la República, previa acusación de la Cámara de Representantes ante el Senado de la República. Mientras no medie la actuación del Congreso, no es posible adelantar acciones legales contra los ciudadanos que temporalmente ostentan la calidad de dignatarios de los máximos tribunales de Justicia.

\section{Reseña de parlamentarios que iniciaron procesos contra miembros de la Rama Judicial}

\section{Jairo Ruíz Medina}

La Constitución expedida en 1991 en Colombia incorporó una institución novedosa en su momento, "la pérdida de investidura", figura mediante la cual el Consejo de Estado podía quitar la investidura a los parlamentarios por violación al régimen de inhabilidades e incompatibilidades por denuncias realizadas por ciudadanos o autoridades sobe el particular.

Debido a lo anterior, durante el año de 1992 el Consejo de Estado mediante decisión de 16 votos contra 6 resolvió decretar la pérdida e investidura del Senador Samuel Alberto Escrucería Manzi debido que mediante providencia de abril de 1992 la Corte Suprema de Justicia confirmo una condena en su contra y por tal motivo no podría continuar siendo parlamentario.

Un ciudadano demando a los 16 consejeros que votaron por la pérdida de investidura de Escrucería por prevari- 
cato $^{19}$, al considerar que por un aspecto reglamentario no podían haber adoptado tal determinación.

El 22 de abril esa denuncia fue repartida en la Comisión de investigación y Acusación al representante Jairo Ruiz Medina, con la finalidad que le diera trámite. El señor Ruiz Medina había sido notificado desde febrero de un proceso contra su investidura ante el Consejo de Estado, razón por la cual debió declararse impedido para adelantar diligencias contra sus jueces.

Ruiz Medina inició el trámite formal del proceso y el 21 de julio ordeno la indagatoria ${ }^{20}$ de los 16 Consejeros de Estado, citando a Guillermo Chaín Lizcano, entonces presidente del Consejo de Estado y ponente de la decisión cuestionada y a Carlos Betancur Jaramillo, ponente en el proceso de desinvestidura adelantado en su contra para practicar la diligencia el 27 de julio.

El día de la citada diligencia, los magistrados citados le hicieron saber al representante que debía apartarse del conocimiento del proceso debido a la actuación que se adelantaba en su contra. Ruiz Medina hizo caso omiso a lo anterior y dio inició a la indagación contra Chaín Lizcano, para posteriormente aceptar la recusación presentada, razón por lo cual el 4 de agosto de 1993 fue apartado del caso. Los demás miembros de la Comisión de Investigación y Acusación no continuaron trámite alguno con ese proceso. De acuerdo al relato de los sucesos que aparece en el diario El Tiempo de julio 28 de 1993, el rechazo a la diligencia realizada por Ruiz fue unánime. Mencionaba éste medio de prensa:

...El magistrado Chaín respondió en forma vehemente y emotiva ese juicio de valor. Quiero decirle al país, a mis hijos, a mi esposa, a los alumnos que tengo por millares en todo el país y a mis amigos, que ni Guillermo Chaín ni los consejeros de Estado llamados a esta indagatoria han cometido ni cometerán delito alguno. Es la primera vez que asisto a una indagatoria... y me duele y me abochorna, agregó. Deploró que estas cosas sucedan en un país que, de acuerdo con sus palabras, primero asesina físicamente a sus jueces y ahora pretende aniquilarlos moralmente (El tiempo 28 de Julio de 1993).

19 El prevaricato es un delito que consiste en la expedición por parte de un servidor público de una resolución, dictamen o concepto manifiestamente contrario a la ley. En este caso, el denunciante consideraba que los magistrados habían cometido este delito al iniciar una investigación contra los representantes.

20 La indagatoria es la diligencia mediante la cual se recibe la declaración de la persona que es investigada por un presunto hecho delictivo.
La actuación temeraria de Ruiz Medina se concreto en iniciar una investigación contra funcionarios que lo investigaban a él con anterioridad y citarlos a rendir su testimonio.

El parlamentario fue denunciado ante la Sala Penal de la Corte Suprema de Justicia por el delito de Prevaricato por Acción. Fue llamado a juicio y mediante sentencia de marzo 19 de 1998 fue condenado a 42 meses de prisión y al pago de perjuicios morales ${ }^{21}$ a Guillermo Chaín Lizcano y Carlos Betancur Jaramillo en 500 y 300 gramos oro respectivamente.

Es preciso destacar del análisis realizado por la Corte Suprema de Justicia para la imposición de la indemnización por perjuicios morales en favor de los citados magistrados: No se ordenará indemnización de perjuicios materiales, por cuanto no aparece acreditado que con la comisión del punible se hubiere irrogado daño de esta índole a un tercero, no obstante, como en relación con los daños morales no sucede lo mismo, habida cuenta que como lo demuestra el proceso y emana en forma diáfana la arbitraria citación a indagatoria de los Consejeros Guillermo Chaín Lizcano, a quien efectivamente se le recepcionó esta diligencia, y Carlos Betancurt Jaramillo, quien compareció también a la citación sin que rindiera la diligencia por la intervención de la Comisión de Investigación y acusación, les ocasionó una gran afección moral por lo injusto de la medida y por el gran escándalo publicitario que suscitó el hecho, poniendo en tela de juicio su honestidad como jueces, como ellos mismos lo refieren en sus testimonios, dolor que el condenado como causante de ellos debe indemnizar, fijándolos la Corte, de conformidad con el artículo 106 del C. P. en 500 gramos oro para el doctor Chaín Lizcano y 300 para el doctor Betancurt Jaramillo, por cuanto no obra prueba alguna que demuestre que estos ofendidos hayan iniciado la correspondiente acción civil. Respecto de los demás Magistrados citados para indagatoria por el doctor Ruiz Medina y que no alcanzaron a concurrir hasta su Despacho a rendirla, no se pronunciará la Corte sobre esta clase de indemnización, por cuanto se carece dentro del proceso de prueba alguna que demuestre su existencia." ${ }^{\prime 2}$

${ }^{21}$ Se entiende por perjuicios morales "El impacto o sufrimiento psíquico o espiritual producido por la agresión directa de bienes materiales o bien al acerbo extrapatrimonial o de la personalidad", según Santos Briz, Jaime. "la responsabilidad Civil". Derecho Sustantivo y procesal" Madrid:Montecarlo. p. 737.

22 Corte Suprema de Justicia. Proceso de radicación Unica No. 8664 contra Jairo Ruiz Medina. Marzo 19 de 1998 con ponencia del Magistrado Carlos A. Galvez Argote. 


\section{Pablo Ardila Sierra}

El 6 de julio de 1996 finalizo en la Cámara de Representantes el proceso seguido contra el Presidente Ernesto Samper Pizano por la financiación de su campaña presidencial con dineros provenientes de un grupo de narcotraficantes.

La plenaria de la cámara bajo por una votación de 111 a 43 decidió archivar el proceso seguido contra el mandatario y como consecuencia de ello nunca se llegó a la etapa de juicio al Senado de la República.

Para algunos ciudadanos, los representes había actuado haciendo caso omiso a las pruebas que existían de la responsabilidad de Samper Pizano y en razón a ello presentaron denuncias contra los congresistas que votaron a favor de archivar el proceso para que se les investigara por el delito de prevaricato por acción.

La Sala Penal de la Corte Suprema de Justicia dio inició a la investigación y comenzó a citar a los parlamentarios que votaron en favor del Presidente para indagar si habían actuado contrariando la ley penal.

El 20 de julio de 1998 se posesionó el congreso elegido para el periodo constitucional 1998-2002. En la Comisión de Acusaciones de la Cámara de Representantes fue designado, entre otros, el representante Pablo Ardila Sierra. ${ }^{23}$

En dicha Comisión fueron denunciados por el entonces senador Carlos Alonso Lucio ${ }^{24}$ los magistrados de la Sala Penal de la Corte Suprema de Justicia por el delito de prevaricato, al considerar el denunciante que las investigaciones adelantadas contra los representantes que votaron a favor de Samper Pizano eran ilegales.

23 Pablo Ardila Sierra. Político colombiano. Fue elegido Representante a la Cámara por la ciudad de Bogotá 'para el periodo 1998-2002. Posteriormente fue elegido Gobernador del Departamento de Cundinamarca para el periodo 2004-2007. Días antes de finalizar su periodo como Gobernador, fue detenido por orden de la Fiscalía General de la Nación. Luego de estar detenido por más de dos años y diez meses recuperó su libertad en septiembre de 2010. No obstante lo anterior, para agosto de 2011,44 meses después de su detención no había finalizado el juicio que se adelanta en su contra.

24 Carlos Alonso Lucio. Exguerrillero del Movimiento M-19. Luego de participar en el acuerdo de paz entre el Gobierno y dicha organización, participo en política siendo elegido Representante a la Cámara para el periodo 1994-1998 y Senador de la República para el periodo 1998-2002. Fue procesado y condenado por la Corte Suprema de Justicia por el delito de falsa denuncia. En su momento, se considero que la denuncia presentada contra los magistrados de la Corte tenía como motivación última el separarlos del conocimiento de la investigación en su contra..
La denuncia fue asignada al representa Ardila Sierra, quien luego de abrir formalmente la investigación procedió a mediados de octubre de 1998 a llamar a indagatoria a los nueve magistrados de la Sala Penal de la Corte Suprema de Justicia por la denuncia realizada por Lucio.

El 22 de octubre de 1998 rindió indagatoria el magistrado Jorge Anibal Gómez Gallego. Los magistrados de la Sala Penal enviaron una comunicación a la Cámara de Representantes, donde solicitaron la revisión del proceso adelantado por Ardila según informaba el diario El Tiempo en su edición de octubre 23 de 1998. Como consecuencia de lo anterior, fueron asignados dos representantes adicionales, que realizarían conjuntamente con Ardila la instrucción del expediente. Después de ello, nunca volvieron a ser citado a ninguna diligencia los magistrados del alto tribunal por estos hechos.

Mediante la Sentencia No. SU-047 de enero 29 de 1999 la Corte Constitucional al amparar el derecho fundamental al debido proceso de la exrepresentante a la Cámara Viviane Morales Hoyos, considero que las actuaciones de los parlamentarios dentro de los procesos judiciales que realizan en ejercicio de sus funciones están protegidas por la inviolabilidad del voto consagrado en la Constitución Política de Colombia y por ello carece de competencia la Corte Suprema de Justicia para adelantar procesos judiciales por el sentido del voto de los congresistas. Con base a la anterior decisión, fueron archivados los procesos judiciales que había iniciado la Sala Penal de la Corte Suprema de Justicia contra los 111 parlamentarios que votaron favorablemente el archivo del proceso contra el Presidente Samper. ${ }^{25}$

El representante Ardila fue denunciado en noviembre de 1998 ante la Sala Penal de la Corte Suprema de Justicia por prevaricato por acción al haber iniciado una investigación contra los magistrados de esa sala y haberlos llamado a indagatoria. Debido a que los magistrados no podían iniciarle procesos a Ardila, se declararon impedidos y fueron nombrados unos conjueces que adelantaran el proceso.

En marzo de 1999 la sala de conjueces resolvió abrir investigación contra el representante Ardila Sierra. ${ }^{26}$ En mayo de 2000, se ordeno la detención del exrepresentante. ${ }^{27} \mathrm{El}$ 31 de Octubre de 2000, el diario El Tiempo informaba de la siguiente manera lo ocurrido en el proceso:"

\footnotetext{
25 Con relación al asunto de la inviolabilidad de los congresistas, puede consultarse la tesis de grado Inviolabilidad Congresional realizada por el suscrito y Navi Guillermo Lamk Castro donde se aborda el concepto, desarrollo constitucional y jurisprudencial de la institución. Pontificia Universidad Javeriana 2000.

26 Diario EL TIEMPO, sección Nación marzo 26 de 1999

27 Diario EL TIEMPO, Seción Política, mayo 16 de 2000.
} 
...La Corte Suprema de Justicia llamó ayer a juicio al ex representante Pablo Ardila Sierra por el delito de prevaricato por acción. El proceso se originó en 1998 cuando Ardila era investigador de Comisión de Acusaciones de la Cámara y citó a indagatoria a todos los integrantes de la Sala Penal de la Corte por abrirle investigación a los 109 congresistas que juzgaron al ex presidente Ernesto Samper (El Tiempo, octubre 31 de 2000).

La Corte Constitucional mediante la Sentencia No. SU062 de Enero 24 de $2001^{28}$ fallo a favor de Pablo Ardila Sierra una Acción de Tutela interpuesta contra la Sala Penal de la Corte Suprema de Justicia, al considerar que las acciones que adelantó en su calidad de representante investigador estaban protegidas por la inviolabilidad parlamentaria que es una garantía que comprende también la función jurisdiccional que se les asigna a los congresistas en la Constitución. Por lo anterior, dejó sin efectos el proceso que le seguía la Corte Suprema de Justicia y ordenó su inmediata libertad.

En síntesis, los representantes que han impulsado procesos contra miembros de las Altas Cortes de Justicia han terminado en prisión. El representante Ruiz Medina fue condenado a prisión por dar inicio a una diligencia contra un magistrado del Consejo de Estado y haber citado a esta misma diligencia a otro. Incluso, fue condenado a pagar los perjuicios morales sufridos por los citados. El representante Ardila estuvo en prisión durante más de un semestre por haber realizado una diligencia de indagatoria a un magistrado y haber citado a los restantes miembros de la Sala Penal de la Corte Suprema de Justicia.

Dejando de un lado el debate jurídico sobre la legitimidad del inicio o no de las investigaciones en los casos relacionados, se evidencia desde el punto de vista práctico que nunca se logró avanzar mínimamente en los procesos contra los magistrados y que la reacción a las citaciones realizadas marco un precedente para los parlamentarios que pudieran tener que adelantar investigaciones contra miembros de la Rama Judicial. ¿Qué parlamentario arriesgara su carrera política para "citar" a una declaración a un funcionario judicial? La respuesta, trece años después de la última citación es clara: Ninguno.

\section{La Intangibilidad de los miembros de la cúpula de la Rama Judicial}

La demostrada imposibilidad de adelantar procesos contra magistrados de Altas Cortes de Justicia en Colombia

28 El fallo tuvo 5 votos a favor y 4 en contra. Los últimos consideraban que debía continuarse el procesamiento del parlamentario. a pesar de estar diseñado el procedimiento formal en la Constitución Nacional ha tenido como consecuencia la aparición de un nuevo principio o institución que podemos denominar como la intangibilidad de los integrantes de los altos tribunales de justicia. Entendemos que la intangibilidad es algo que tiene la cualidad de intangible, y por éste término: "Que no debe o no puede tocarse" (Real Academia Española, 1992).

Esta institución correspondería a la especie informal debido a que es una modificación de una regla formal fruto de una práctica repetida pública, la cual es, la imposibilidad de adelantar procesos contra determinados funcionarios públicos. Su fuente no es una manifestación legal sino una costumbre que parece aumentar de modo incremental en el tiempo (Douglas,1993).

Una de las causas del surgimiento y fortalecimiento de la intangibilidad a miembros del poder judicial se soporta en la poca confianza que se guarda en el Congreso de la República, órgano que representa el poder legislativo mediante el Senado de la República y la Cámara de Representantes, encargado de adelantar el proceso legal contra los magistrados, institución que mantiene un bajo índice de aprobación ciudadana.

En las mediciones que realiza anualmente la Organización No Gubernamental Transparencia Internacional, el Congreso siempre comparte con los partidos políticos, los primeros lugares de percepción de corrupción por parte de los ciudadanos. ${ }^{29}$

Lo anterior trae como resultado la desconfianza en las actividades que debe desarrollar la rama legislativa de poder público. En una encuesta publicada en agosto de 2011 por la Revista Credencial sobre corrupción y confianza en las instituciones colombianas, el Congreso se ubicó en el puesto 12 entre 13 instituciones, con un porcentaje de confianza de apenas el 32\% (Revista Credencial, 2011).

No es difícil presumir que si la imagen del legislativo está tan deteriorada entre los ciudadanos, la función de juzgamiento de altos funcionarios que tiene encomendada por disposición constitucional tiende a volverse ineficaz e imposible de desarrollar, pues carece de respaldo popular y no tendría sustento que quienes peor margen de confianza tienen entre la opinión pública, puedan desarrollar está función. En otras palabras, se ha dejado al Congreso sin legitimidad para ejercer funciones judiciales.

29 Barometro Global de la Corrupción Transparencia Internacional, 2004-2011. 
Los funcionarios que por fuero constitucional deben ser procesados por el Congreso de la República ${ }^{30}$ no tienen en la realidad juez que impulse procesos en los cuales son denunciados, situación que origina de facto dos consecuencia fatales para un Estado Democrático, estas son, de una parte un rompimiento de la igualdad constitucional de todos los individuos, al conformarse una "categoría especial" de ciudadanos que no son juzgados por sus conductas, y de otra, la pérdida de contrapeso del poder judicial, debido a que no existe autoridad ante la cual sus máximos funcionarios, los magistrados de las cortes jerárquicamente más importantes del Estado, deban responder por las acciones $\mathrm{u}$ omisiones en que incurran en cumplimiento de sus funciones.

La ocurrencia de esta situación trae consecuencias que resquebrajan la organización estatal, entre las cuales mencionaremos.

\section{Rompimiento del principio de igualdad}

Uno de los principios inspiradores de los estados liberales es la igualdad de todos los ciudadanos ante la ley. Incluso, en el Estado Social de Derecho se profundiza este principio, indicando que la libertad no solo debe ser formal sino también material o real. Entendemos por igualdad formal, el mismo tratamiento de todos los ciudadanos ante la ley por poseer los mismos derechos sin excepción alguna. Mientras tanto, la actuación del Estado con la finalidad de introducir mayores porciones de justicia redistributiva en la sociedad es lo que se entiende por igualdad material (Santaolalla 2004).

La imposibilidad de adelantar procesos contra los miembros de los máximos tribunales del poder judicial se convierte en un quebrantamiento del principio de igualdad, pues los miembros de éstos tribunales se encuentran en una situación diferente a la del resto de los ciudadanos. El poder normativo de lo fáctico ha evidenciado que a los magistrados de las altas cortes no se les aplica las mismas normas que al resto de los ciudadanos y el mantenimiento y profundización de esta situación, enmarcada precisamente en los guardianes de la ley ocasiona que la fractura del principio igualitario se consolide en el tiempo con la máscara de la independencia del poder judicial y se establezca una norma tácita de intangibilidad de los jueces. Los hechos han creado éste nuevo principio que se promociona como si fuera el verdadero orden de las cosas (Lechner,2006,pp 2000-2004).

30 Presidente y Vicepresidente de la República, Fiscal General de la Nación y Magistrados Altas Cortes.

\section{Inexistencia de controles al Poder Judicial}

Ante la demostrada incompetencia del Juez designado por la Constitución Política para cumplir la función de procesar a los magistrados de las altas cortes de justicia, se configura un vacío institucional que da como resultado la existencia de un poder público cuyos dignatarios ejercen sus funciones sin ninguna clase de control. La existencia de poderes públicos que no rinden cuenta a nadie más que ellos mismos traen como resultado el surgimiento de poderes que no temen incumplir la ley debido a que no temen ser castigados. Entre el año 2009 y 2010 la República de Colombia permaneció dieciséis meses sin Fiscal General de la Nación debido a la negativa de la Corte Suprema de Justicia a elegir dicho funcionario de las ternas presentadas por el Presidente Alvaro Uribe Vélez. Aunque la Constitución le otorga esa función al máximo tribunal de la justicia ordinaria, éste se negó a realizar la elección debido al enfrentamiento público de alguno de sus miembros con el Ejecutivo. Con la llegada del nuevo Presidente de la República y la confección de una nueva terna de candidatos al cargo diferente a la presentada por el gobierno anterior la Corte finalmente eligió en el cargo una candidata sin ningún tipo de experiencia en el campo penal.

Haciendo a un lado las apreciaciones políticas de las razones que ocasionaron que fuera dilatada la decisión, la cuestión al menos teórica que se plantea es si pueden los jueces desconocer la Constitución y la ley por las polémicas que tengan con el Ejecutivo. Si la respuesta es positiva, como lo plantean los sucesos acontecidos, se entra en la órbita de un poder sin control que sólo mide sus acciones por el capricho de sus integrantes, dejando de lado el principio de legalidad que debe enmarcar las actuaciones de todos los ciudadanos y en especial, de los jueces.

\section{Una propuesta de modificación legal que permita el Juzgamiento de Miembros de Altas Cortes}

La ineficiencia del sistema de juzgamiento previsto en la Constitución Política de Colombia ha tenido como resultado la consolidación del principio de imposibilidad de juzgamiento de los Magistrados de las diferentes Cortes de Justicia, quedando en letra muerta lo consagrado en la Constitución y la ley según indicamos en el acápite anterior.

Sería el momento de realizar una reforma institucional que permita la recuperación de la igualdad de todos los ciudadanos ante la ley, al ser formal y realmente posible el escrutinio de los actos de los jueces por un tercero diferente a los mismos. El ajuste debe estimular la activación 
de la institucionalidad que permita dentro del marco del debido proceso el juzgamiento de jueces supremos que por acción u omisión cometan conductas contraías a la ley, por las cuales cualquier ciudadano diferente a ellos debiera acudir a un tribunal de justicia a responder por sus actuaciones.

Se considera que puede encararse el tema del procedimiento para juzgar las acciones de los jueces superiores con base en los siguientes elementos:

1. Competencia: El órgano sobre el cual debe recaer la responsabilidad de adelantar está clase de procesos es el Congreso de la República. El esquema actual de acusación de la Cámara de Representantes y juicio por parte del Senado de la República asegura el derecho de defensa del encartado con esta clase de asunto.

2. Finalidad del Proceso que se sigue ante el Congreso de la República:

...El objetivo central del juicio político es separar del cargo al funcionario acusado y, eventualmente, declararlo "incapaz de ocupar ningún empleo de honor, de confianza o a sueldo en la Nación". El propósito del juicio político no es el castigo del funcionario sino la protección de los intereses públicos contra el peligro $u$ ofensa por el abuso del poder oficial, descuido del deber o conducta incompatible con la dignidad del cargo (García-Mansilla, 2004).

El Congreso no define responsabilidades penales, simplemente separa del cargo al funcionario y en la eventualidad que los cargos formulados constituyan un delito, será la Corte Suprema de Justicia la encargada del juicio penal correspondiente.

Es preciso enfatizar está situación debido a que se tiende a confundir el proceso ante el Congreso con un encausamiento penal. Es fundamental está consideración, pues la excesiva judicialización del proceso seguido por el legislativo es la causa que impide su funcionamiento.

3. La instrucción del Proceso: Entendemos por instrucción el conjunto de actuaciones tendientes a averiguar las circunstancias de tiempo, modo y lugar de la ocurrencia de un hecho que se inicia con la denuncia que se realiza sobre él mismo, incluye la práctica de pruebas que corroboren o desvirtúen la denuncia y finalizan con la decisión de acusación del funcionario indagado o el archivo de las diligencias.
La instrucción ha sido entregada a la Comisión de Investigación y Acusación de la Cámara de Representante que no ha cumplido esta función de manera eficiente. Se propone que esta etapa sea realizada por un Tribunal de Instrucción compuesto por cinco miembros elegidos por la Cámara de Representantes para un periodo de 8 años y que deben cumplir los mismos requisitos legales que para ser integrantes de la Corte Suprema de Justicia.

Una vez finalice el periodo de instrucción, se presenta un informe a la Plenaria de la Cámara y es ésta, la que adopta por mayoría absoluta la decisión de acusar o no ante el Senado de la República al funcionario investigado.

La participación de los Representantes se da única y exclusivamente para la votación de la decisión de acusar ante el Senado de la República o archivar la investigación.

Los términos legales a los cuales se someten las denuncias que se presentan ante la Cámara de Representantes serán iguales a los establecidos en el Código de Procedimiento Penal.

4. El Juicio: La etapa de juicio ante el Senado de la República debe quedar conforme lo señala en la actualidad la Constitución Política.

Según se describió en los acápites anteriores, la falencia que ha permitido la imposibilidad de adelantar está clase de procesos judiciales ha sido además de la voluntad de los representantes, la impericia de quienes debe adelantar estas labores. Profesionalizando la labor instructora se allanaría el camino para lograr que los procesos contra funcionarios beneficiados por el aforo constitucional puedan ser procesados cuando las circunstancias lo ameriten.

\section{Conclusiones}

Cuando se hace referencia a un poder público al que le falta ser controlado, por lo general convenimos que se trata del poder ejecutivo. El presidencialismo existente en América Latina trae como consecuencia que los demás poderes públicos aparezcan casi como subordinados de este otro superpoder. En el caso colombiano, con posterioridad a la Constitución de 1991 el poder judicial adquirió una silenciosa preponderancia que ha hecho sentir mediante decisiones que en no pocas ocasiones se han convertido en políticas públicas de obligatorio cumplimiento para los demás poderes del Estado. Estas nuevas funciones no han tenido contraprestación con relación a 
la exigencia de responsabilidades de los operadores de justicia. Al contrario, pareciera improbable que bajo el actual esquema institucional puedan exigirse responsabilidades a estos funcionarios. Esta situación contrasta con la forma como en el último lustro integrantes de la rama ejecutiva y legislativa han tenido que responder ante la rama judicial por sus acciones $u$ omisiones. Se ha construido una protección alrededor de los jueces que hemos denominado intangibilidad y que en la medida que pasa el tiempo comienza a consolidarse como una institución informal con más importancia y efectividad que las establecidas en la Constitución y las leyes colombianas.

Se considera poco saludable para un Estado de Derecho la inexistencia de control para los miembros del poder judicial, pues el principio de igualdad queda desvirtuado y se afecta seriamente el resto de la institucionalidad.

La reforma al proceso establecido en la Constitución alienta a solucionar el problema de la instrucción, que ha sido identificado por ahora, como el elemento que impide el normal funcionamiento del sistema de juzgamiento a integrantes de Altas Cortes. Sin embargo, como menciona Prats (2002). ...como las instituciones son formales e informales, la simple reforma legislativa no garantiza el enraizamiento del cambio institucional si no va acompañada de un cambio en las actitudes, valores y competencias sociales capaz de insertar en la cultura política las nuevas reglas.

Luego de la fracasada reforma a la justicia de 2012 parece lejana la posibilidad de una modificación al procedimiento para el enjuiciamiento de miembros de las altas cortes de justicia en Colombia. De no corregirse esta situación, las palabras de J.J. Rousseau en su Carta a la República de Ginebra de mediados del siglo XVIII, cobrarían una singular vigencia, al manifestar que

...hubiera, pues, querido que nadie dentro del Estado hubiera podido creerse por encima de la ley, y que nadie desde afuera hubiera podido tampoco imponer al estado aquel reconocimiento. Porque, cualquiera que sea la constitución de un gobierno, si en ese pueblo hay un solo hombre que no esté sometido a la ley, todos los demás siguen necesariamente su misma conducta.

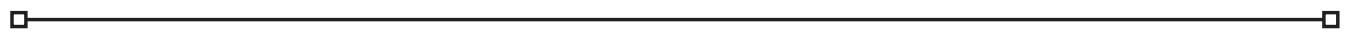

\section{Referencias}

Carrillo Flores, F (1999). Los retos de la reforma de la justicia en América Latina. En Reforma Judicial en América Latina: una tarea inconclusa. Bogotá: Corporación Excelencia en la Justicia.

Castagnola, A. (2010). La Diversidad Institucional de los Poderes Judiciales Provinciales en Argentina desde una perspectiva histórica, en Revista PostData Volumen 15, Octubre 2010/No.2, Edic. Grupo Interuniversitario Postdata, Buenos Aires.

Diario El Tiempo (1993). Quieren Aniquilarnos Moralmente. Sección Información General Auto Jorge Gonzalez, 28 de julio de 1993

Diario El Tiempo (1998). Pablo Ardila apoyado en diligencias vía celular. Octubre 23 de 1998.

Leiras M (2004). ¿De qué hablamos cuando hablamos de instituciones informales?, en Arturo Fernández, Comp. Estudios de Política Comparada. Rosario: Universidad Nacional de Rosario.

Lechner N (2006), La Crisis del Estado en América Latina, Obras Escogidas, Editorial LOM, Santiago de Chile.

Montesquieu Ch (2000). Capítulo VI Ediciones Istmo .

North, D (1993) Instituciones, cambio institucional y desempeño económico. Fondo de Cultura Económico México.

Prats J (2002) Instituciones y desarrollo en América Latina ¿Un rol para la ética?, junio de 2002 disponible en http:/ / www. uoc.edu/web/esp/art/uoc/prats0502/prats0502.html consultado abril 10 de 2012.

Proyecto sobre Independencia y Acceso a la Justicia en América Latina http://www.apdh-argentina.org.ar/piajal/ proyecto.htm. Consultado abril 16 de 2012. 
Quinche Ramírez F (2009). Derecho Constitucional Colombiano De la carta de 1991 y sus Reformas. Tercera Edición, Editorial Universidad del Rosario, Bogotá.

Real Academia Española (1992) Diccionario de la Lengua Española, 21. Edición, Madrid.

García- Mansilla M (2004) La Corte Suprema y el Juicio Político. Públicado en Diario de Doctrina y Jurisprudencia El Derecho, Buenos Aires, viernes 4 de junio de 2004.

Rousseau J, Discurso sobre el origen de la desigualdad entre los hombres,(1754) 2007, Ediciones Folio, España.

Santaolalla López F (2004), Derecho Constitucional. Edit Dykinson, Madrid.

Santos Briz, J.(1986) La responsabilidad Civil. Derecho Sustantivo y procesal: Montecarlo. Madrid

Transparencia. Barometro Global de la Corrupción. Transparencia Internacional, 2004-2011disponible en www.transaprencia.org.es . consultado abril 10 de 2012

Vargas Hernández J. (2005) Análisis de Fundamentos de la Teoría Institucional en Revista Digital Universitaria, México, Universidad Autónoma de México, Volumen 6 disponible en www.revista.unam.mx/vol6/num8/art84/ ago_art84.pdf consultado abril 10 de 2012. 